\title{
Hepatopancreas immune response during molt cycle in the mud crab, Scylla paramamosain
}

\begin{abstract}
Zhanning $\mathrm{Xu}^{1}$, An Liu ${ }^{1}$, Shengkang $\mathrm{Li}^{2}$, Guizhong Wang ${ }^{1}$ \& Haihui Ye $\mathrm{I}^{1 凶}$
Molt is a critical developmental process in crustaceans. Recent studies have shown that the hepatopancreas is an important source of innate immune molecules, yet hepatopancreatic patterns of gene expression during the molt cycle which may underlie changes in immune mechanism are unknown. In this study, we performed Illumina sequencing for the hepatopancreas of the mud crab, Scylla paramamosain during molt cycle (pre-molt stage, post-molt stage, and inter-molt stage). A total of $44.55 \mathrm{~Gb}$ high-quality reads were obtained from the normalized cDNA of hepatopancreas. A total of 70,591 transcripts were assembled; 55,167 unigenes were identified. Transcriptomic comparison revealed 948 differentially expressed genes (DEGs) in the hepatopancreas from the three molt stages. We found that genes associated with immune response patterns changed in expression during the molt cycle. Antimicrobial peptide genes, inflammatory response genes, Toll signaling pathway factors, the phenoloxidase system, antioxidant enzymes, metal-binding proteins and other immune related genes are significantly up-regulated at the post-molt stage and inter-molt stage compared with the pre-molt stage, respectively. These genes are either not expressed or are expressed at low levels at the pre-molt stage. To our knowledge, this is the first systematic transcriptome analysis of genes capable of mobilizing a hepatopancreas immune response during the molt cycle in crustaceans, and this study will contribute to a better understanding of the hepatopancreas immune system and mud crab prophylactic immune mechanisms at the post-molt stage.
\end{abstract}

In crustaceans, molt is an essential characteristic of the organism's development; in order to grow, the animal must shed the old exoskeleton and construct a new one ${ }^{1-4}$. The crustacean molt cycle affects the status of a number of physiological processes, including the interaction with environmental stressors and disease agents ${ }^{5,6}$. In crustaceans, several researchers have described studies of molt susceptibility to pathogenic infections. Corteel et al. ${ }^{7}$ reported that the Pacific whiteleg shrimp, Litopenaeus vannamei at post-molt stage is more susceptible to white spot syndrome virus (WSSV) infection than at pre-molt stage. Tumburu et al. ${ }^{8}$ have also shown that pesticide-virus interactions lead to increasingly higher susceptibility to acute toxicity at post-molt stage in $L$. vannamei. These studies indicate that crustaceans display susceptibility to pathogenic infections that vary during the molt cycle.

The hepatopancreas is an important organ involved in the process of crustacean molting, and plays a vital role in energy storage and breakdown, nutrient accumulation, and carbohydrate and lipid metabolism ${ }^{9}$. Growth and developmental metabolism related genes that are involved in the formation of the molt have been isolated in crustaceans. However, despite extensive research, the changes in hepatopancreas immune response during the molt cycle in crustaceans still remain poorly understood. Recent findings show that the hepatopancreas is an integrated organ of immunity and metabolism, which is an important source of innate immune molecules in crustaceans $s^{10-13}$, while nutrition and metabolic regulation may have an impact on the efficiency of the immune response in the hepatopancreas ${ }^{14}$. At post-molt stage, in light of the soft body, lack of exoskeleton protection, and susceptibility to various pathogens, crustaceans may mobilize the body's immune defense ${ }^{4}$.

Mud crabs (Scylla species) are found throughout tropical and warm temperate zones in the Indo-Pacific, and S. paramamosain is a commercially important marine fishery species in the Southeast coast of China ${ }^{15}$. Transcriptomics is an emerging discipline, which can now be used to examine patterns of gene transcription relative to crustacean immunity, growth and molting ${ }^{12,14,16}$. In this study, we used RNA-Seq to investigate the 


\begin{tabular}{|l|l|}
\hline Description & Number \\
\hline Clean sequencing reads & $176,833,411$ \\
\hline Clean reads & $4.5 \times 10^{10}$ \\
\hline Total nucleotides (bp) & $50.88 \%$ \\
\hline Percentage of GC content (\%) & \multicolumn{2}{|l}{} \\
\hline Alignment statistics & $134,832,741$ \\
\hline Mapped reads & $76.25 \%$ \\
\hline Mapped ratio & \\
\hline Assembly statistics & 70,591 \\
\hline The number of transcript & 55,167 \\
\hline The number of unigene & \\
\hline Annotation & 7,742 \\
\hline COG & 8,260 \\
\hline GO & 10,495 \\
\hline KEGG & 15,436 \\
\hline KOG & 19,147 \\
\hline Pfam & 21,846 \\
\hline Swissprot & 21,764 \\
\hline NCBI-NR &
\end{tabular}

Table 1. Summary of sequence analysis in S. paramamosain hepatopancreas.

\begin{tabular}{|l|l|l|l|}
\hline All genes & Significant DEGs $($ Padj $<\mathbf{0 . 0 1})$ \\
\hline Cond.1 & Cond.2 & Up-regulation $($ Cond.2 $>$ Cond.1) & Down-regulation $($ Cond.2 $<$ Cond.1) \\
\hline Post-molt stage & Inter-molt stage & 5 & 1 \\
\hline Inter-molt stage & Pre-molt stage & 188 & 601 \\
\hline Pre-molt stage & Post-molt stage & 142 & 11 \\
\hline
\end{tabular}

Table 2. Statistics of DEGs in the hepatopancreas transcriptome of S. paramamosain. Padj $p$ value adjusted for multiple testing using Benjamini-Hochberg.

immune responses in the hepatopancreas at three molt stages in the mud crab, S. paramamosain to understand the mechanism of immune defense during the crustacean molt cycle.

\section{Results}

Sequencing and de novo assembly of hepatopancreas transcriptome. After sequencing, quality trimming, and adapter clipping, a total of 176,833,411 paired-end reads were obtained from 9 samples at the three molt stages (post-molt stage, inter-molt stage and pre-molt stage) and used for de novo assembly. We obtained 70,591 transcripts after assembly, and 55,167 unigenes were identified (Table 1).

Identification of differentially expressed genes (DEGs). In this study, the analysis of hepatopancreas transcriptome data revealed that 948 DEGs were annotated successfully across the three molting stages (Table 2). We found that the DEGs between the post-molt stage and inter-molt stage were relatively few, with only 6 genes identified. The DEGs between inter-molt and pre-molt stage, or between post-molt and pre-molt stage were substantially more, being 789 and 153 genes, respectively.

Functional classification of DEGs of hepatopancreas. Assembled non-redundant unigenes were subjected to Gene Ontology $(\mathrm{GO})^{17}$, Clusters of Orthologous Groups $(\mathrm{COG})^{18}$ and Kyoto Encyclopedia of Genes and Genomes (KEGG) ${ }^{19}$ databases for blast searching ${ }^{20}$. GO annotation output showed that the unigenes could be assigned to three parts: biological processes, cellular components, and molecular functions. GO function classification was performed with DEGs. In the hepatopancreas, compared post-molt stage and inter-molt stage, the three major functional categories (biological process, cellular component, and molecular function) were not found in the GO terms associated with significant DEGs. When inter-molt stage and pre-molt stage were compared, the DEGs were assigned to 36 terms, of which dominant subcategories included single-organism process (64 genes) and metabolic process (84 genes) in the category of biological process, organelle (23 genes) and cell part (23 genes) in cellular component, and catalytic activity (149 genes) in molecular function, respectively (Fig. 1a). In the comparison of pre-molt stage and post-molt stage, metabolic process (33 genes) was the top abundant terms in biological process. While, extracellular region (6 genes) and catalytic activity (49 genes) were the top terms in the cellular component and molecular function, respectively (Fig. 1b) (Supplementary data 1). 
To classify orthologous gene products, COG function classification was performed with significant DEGs. In the hepatopancreas, DEGs at post-molt stage and inter-molt stage were not found in the COG annotations. In the comparison of inter-molt stage and pre-molt stage, the cluster of "general function prediction only" $(36,16.51 \%)$ represented the largest group, followed by "amino acid transport and metabolism" (34, 15.6\%), "carbohydrate transport and metabolism" (31, 14.22\%), "Secondary metabolism biosynthesis, transport and catabolism" (26, $11.9 \%)$, "lipid transport and metabolism" (25, 11.47\%) and "inorganic ion transport and metabolism" $(15,6.88 \%)$, whereas "coenzyme transport and metabolism" $(1,0.46 \%)$ was the group with the lowest number of identifiable consensus sequences (Fig. 2a). In the comparison of pre-molt stage and post-molt stage, the cluster of "carbohydrate transport and metabolism" $(15,23.81 \%)$ represented the largest group, followed by "amino acid transport and metabolism" (10,15.87\%), "lipid transport and metabolism" $(9,14.29 \%)$, "general function prediction only" $(9,14.29 \%)$, "Secondary metabolism biosynthesis, transport and catabolism" $(8,12.7 \%)$ and "energy production and conversion" $(4,6.38 \%)$, whereas "coenzyme transport and metabolism" $(1,1.59 \%)$ was the group with the lowest number of identifiable consensus sequences (Fig. 2b) (Supplementary data 2).

KEGG enrichment results were not obtained from 6 DEGs in the post-molt stage and inter-molt stage comparisons. KEGG enrichment was carried out on 789 DEGs obtained from an inter-molt stage and pre-molt stage comparison, among which 268 DEGs were classified into cellular processes, environmental information processing, metabolism (Fig. 3a). In cellular processes, fourteen genes were assigned to lysosome (ko: 04142) and four genes were assigned to phagosome (ko: 04145); In environmental information processing, one gene related to signal transduction was assigned to FoxO signaling pathway (ko: 04068); In metabolism, carbon metabolism (ko: 01200) and glycine, serine and threonine metabolism (ko: 00260) were the top two pathway (21genes). KEGG enrichment was carried out on 153 DEGs obtained from a pre-molt stage and post-molt stage comparison, among which 67 DEGs were classified into cellular processes, metabolism and organismal systems (Fig. 3b). In cellular processes, five genes were assigned to lysosome (ko: 04142) and one gene was assigned to phagosome (ko: 04145); In metabolism, amino sugar and nucleotide sugar metabolism (ko: 00520) and starch and sucrose metabolism (ko: 00500) were the top two pathways (14 genes); In organismal systems, one gene related to carbohydrate digestion and absorption was identified (ko: 04973) (Supplementary data 3).

DEGs in the hepatopancreas transcriptome related to immune system. To date, there have been few studies on the immune system in the hepatopancreas of the mud crab. DEGs identified across the different molt stages (post-molt stage, inter-molt stage, and pre-molt stage) were compared pair-wise, and genes related to immune response were screened. Expression abundance of the genes showed a significant difference. Among them, we focused on key genes involved in Toll, immune deficiency (IMD) signaling pathways, immune-related and cytokines (Table 3). We found a large number of highly significant up-regulated immune response genes during the post-molt stage and the inter-molt stage, however, these genes are significantly down regulated and not expressed at the pre-molt stage (Fig. 4) (Supplementary data 4).

Transcript validation by qRT-PCR. Twelve immune response genes that identified as differentially expressed genes (DEGs) at post-molt and inter-molt relative to pre-molt were examined by qRT-PCR, and the expression levels of these immune genes were significantly associated with the RNA-seq results (Fig. 5). Our results confirmed the reliability of RNA-seq and accuracy of the Trinity assembly.

\section{Discussion}

In this study, we assembled the hepatopancreas transcriptomes at post-molt, inter-molt and pre-molt stages, and obtained an annotated transcriptome over the molt cycle of the mud crab, S. paramamosain. We found classifications of DEGs from GO, COG and KEGG databases, which were involved in energy metabolism, growth development, osmotic pressure regulation and immune-related processes, this phenomenon demonstrated the major physiological changes happen during molt cycle in S. paramamosain. Compared with pre-molt stage, a large number of genes were up-regulated at the post-molt stage and the inter-molt stage, which further showed that the hepatopancreas is an important organ involved in molt cycle in S. paramamosain. It is interesting to note that some immune-related genes (antimicrobial peptide genes, inflammatory response genes, Toll signaling pathway factors, phenoloxidase system, antioxidant enzymes, metalloproteins, etc.) were significantly up-regulated at the post-molt stage and the inter-molt stage compared with the pre-molt stage, respectively. This might indicate that the mud crabs are sensitive to environmental and physiological changes, and therefore adopt prophylactic immune mechanisms. Similar patterns exist in the life cycle of the swimming crab, Portunus trituberculatus, the chitinase gene PtCht-1 involved in immune defense is highly expressed at post-molt stage and inter-molt stage, but has a low expression at pre-molt stage ${ }^{21}$. It was also reported that the expression of antimicrobial peptides (AMPs) during molt cycle is associated with prophylactic innate immunity in the fruit fly Drosophila melanogaster, which acts to prevent infection ${ }^{22}$.

Antimicrobial proteins (AMPs). Three unique AMP genes were discovered in the hepatopancreas cDNA library, and they showed a significant upregulation at post-molt stage and inter-molt stage.

Crustins are a cysteine-rich cationic peptide with a characteristic four-disulphide core-containing whey acidic protein (WAP) domain ${ }^{23}$, which has antimicrobial activity against Gram-positive bacteria and no activity against Gram-negative bacteria ${ }^{24}$.

SpHyastatin was first screened as a new cationic antimicrobial peptide in the suppression subtractive hybridization (SSH) cDNA library constructed from the hemocytes of $S$. paramamosain ${ }^{25,26}$. The previous study has proved that $S p H y a s t a t i n$ can effectively kill microbes via a permeabilizing mechanism and bind to various anionic cell wall components against different species of bacteria ${ }^{27}$. 

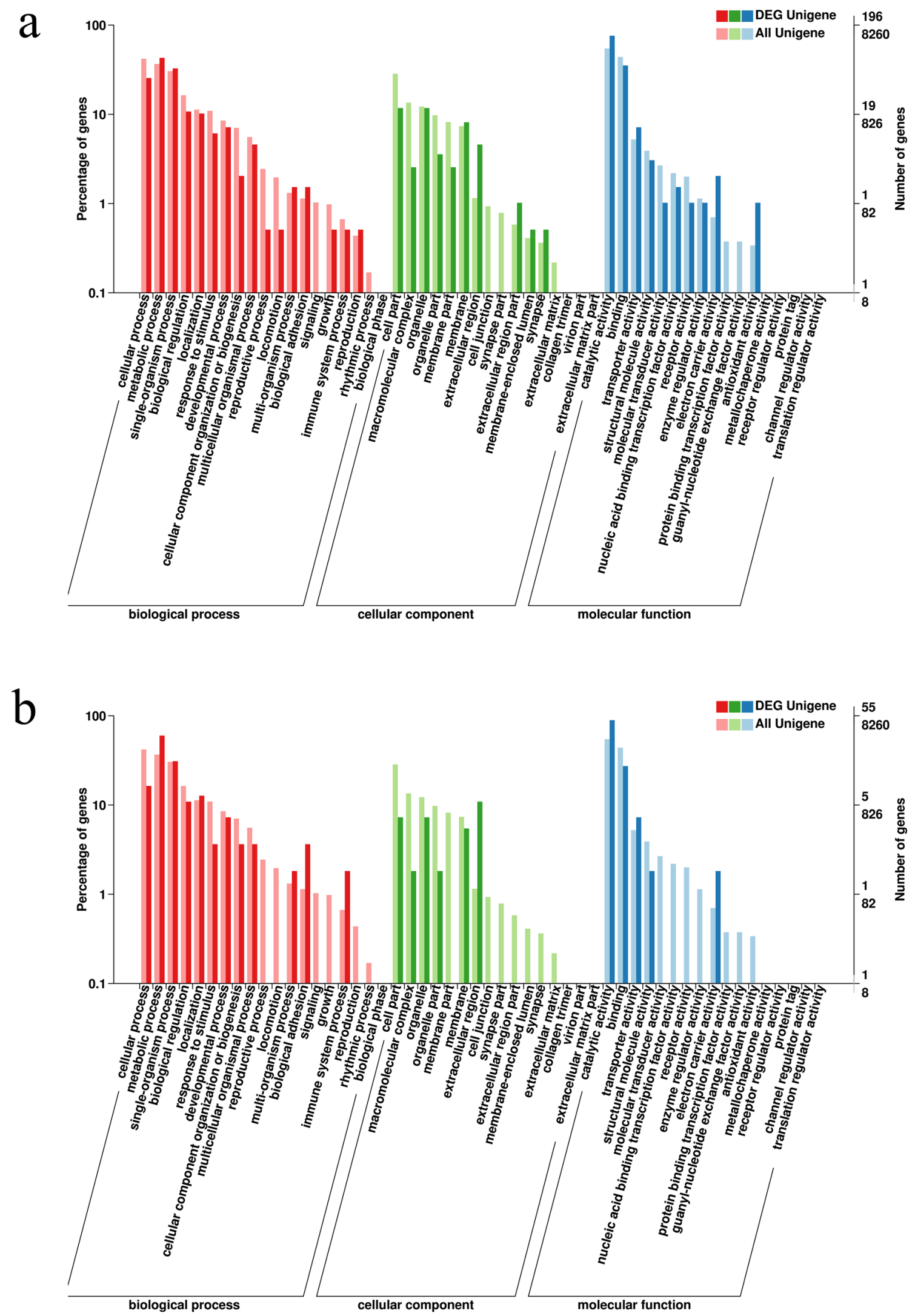
\Figure 1. Distribution of Gene Ontology (GO) functional categories for S. paramamosain hepatopancreas transcriptome. (a) Functional classification of DEG unigenes compared between inter-molt stage and pre-molt stage in the GO database; (b) Functional classification of DEG unigenes compared between pre-molt stage and post-molt stage in the GO database; GO functional categories is mined here from https://www.geneontology.org. Note: the $\mathrm{x}$-axis indicates the secondary classification of the GO database; the y-axis on the left side indicates the ratio of the number of genes annotated to this GO classification to all genes (the denominator of 'All Unigene' is all unigenes, and the denominator of 'DEG Unigene' is all DEG unigenes). The y-axis on the right side indicates the number of genes annotated to this GO entry. The number above represents the number of DEG unigenes, and the number below represents the number of all unigenes.

Lysozymes are immune effectors widely distributed and involved in many physiological processes, such as in immune and digestive systems ${ }^{28,29}$, exerting cytosolic activity on peptidoglycans of bacterial cell walls to initiate cell lysis ${ }^{30}$. In S. paramamosain, lysozyme exhibited moderate antimicrobial activity and possessed weak isopeptidase activity and had a strong binding activity to lipopolysaccharide from Escherichia coli and lipoteichoic acid and peptidoglycan (PGN) from Staphylococcus aureus ${ }^{30}$.

Inflammatory gene IL-16. As a pro-inflammatory cytokine, Interleukin-16 (IL-16) was first identified as a lymphocyte chemoattractant factor in $1982^{31}$. IL-16 regulates migration, proliferation and activation of various cells, as well as the release of pro-inflammatory cytokines ${ }^{32-34}$. A recent study revealed that IL-16 might play a vital role in initiating innate immune responses against pathogen infection in S. paramamosain ${ }^{35}$.

Prophenol/phenol oxidase cascade. In the present study, proteases and inhibitors in the phenol oxidase system were significantly up-regulated at the post-molt stage. In crustaceans, the prophenoloxidase activating system (proPO-system) is an important immune defense system. Serine proteases (SPs) constitute one of the largest families of enzymes in the animal kingdom and play important roles in immune responses ${ }^{36}$. In crustaceans, trypsin-like serine proteases have been isolated from the hepatopancreas of the redclaw crayfish, Cherax quadricarinatus and the Chinese shrimp, Fenneropenaeus chinensis, which are involved in the innate immune defense against pathogens ${ }^{36,37}$. Serine proteinase homologs were also obtained from S. paramamosain, it is suggested that $S p-S P H$ protein could bind to a number of bacteria and play a key role in host defense against microbe invasion ${ }^{38}$.

Pacifastin and alpha2-macroglobulin ( $(2 \mathrm{M})$, ubiquitous protease inhibitors, are involved in the regulation of the prophenyloxidase (proPO) system to avoid the deleterious effects of its active components ${ }^{39-41}$. The expression of these genes is presumed to be due to the activation of the proPO serine proteinase cascade, the over-activated protease is very harmful to cells and tissues, so the expression of serine protease inhibitors is used to control excessive immune responsiveness to maintain homeostasis ${ }^{39,40}$.

Toll signaling pathway. In this study, the expression of the gene coding for the Toll-like receptor was significantly up-regulated at the post-molt stage and inter-molt stage. The Toll signaling pathway is one of the most important innate immune pathways in invertebrates and has a homologous similarity to the mammalian TLR pathway $^{41}$. Toll/Toll-like receptors (TLRs) were the first pattern recognition receptors (PRRs) identified to play a crucial role in innate immune responses in crustaceans. Up to now, TLRs have been cloned and characterized in a limited number of crustacean species, which suggested that TLRs could regulate the transcripts of several AMPs (SpALF1-6, SpCrustin, SpHistin, SpArasin, SpGRP and SpHyastatin) $)^{42-47}$. It is possible that the Toll signaling pathway is activated to regulate the expression of downstream antimicrobial peptides at the post-molt stage, and the expression of antimicrobial peptides was up-regulated in response to different potential pathogens as mentioned above. In addition, we also screened genes related to the Toll pathway, such as Toll-6, dorsal, pellelike kinase, Myd88 and tumor necrosis factor receptor-associated factor 6 (TRAF6). According to the FPKM data, there are no significant differences at the post-molt stage and inter-molt stage compared with the pre-molt stage, respectively, so they were not listed in Table 3. These genes are the homologs of Drosophila Toll pathway genes and involved in Toll-mediated immune defense ${ }^{48}$. It has been reported that the expression profiles of genes involved in the Toll pathway up-regulated at different time points in crustaceans ${ }^{48-50}$.

Antioxidant enzymes. The present study found that the expression of catalase and thioredoxin were significantly up-regulated after molt, possibly due to the large amount of reactive oxygen species produced by oxidative stress at the post-molt stage. Antioxidant enzymes play essential roles in antioxidant responses caused by pathogen invasion or metabolic process ${ }^{51}$. Catalase is involved in the immune response and plays a role in the protection against oxidative stress in S. paramamosain ${ }^{52}$. Thioredoxin, with a redox active disulfide bridge, is responsible for maintaining the balance of reactive oxygen species, which has an important impact on the immune system ${ }^{53,54}$. Thioredoxin has been cloned and characterized in S. paramamosain and may prove to be a potential biomarker gene for evaluation of environmental stress in marine species ${ }^{55}$.

Metal-binding proteins. Two meta-binding proteins were significantly up-regulated at the post-molt stage in S. paramamosain. We infer that the tight regulation of ferritin and zinc protease were a primary defense mechanism to resist microbial infection. Metal-binding proteins are involved in many physiological processes, ranging from immune responses to cellular signaling pathways ${ }^{56}$. Ferritin is a metal-chelator protein involved 


\section{a COG Function Classification of Consensus Sequence}

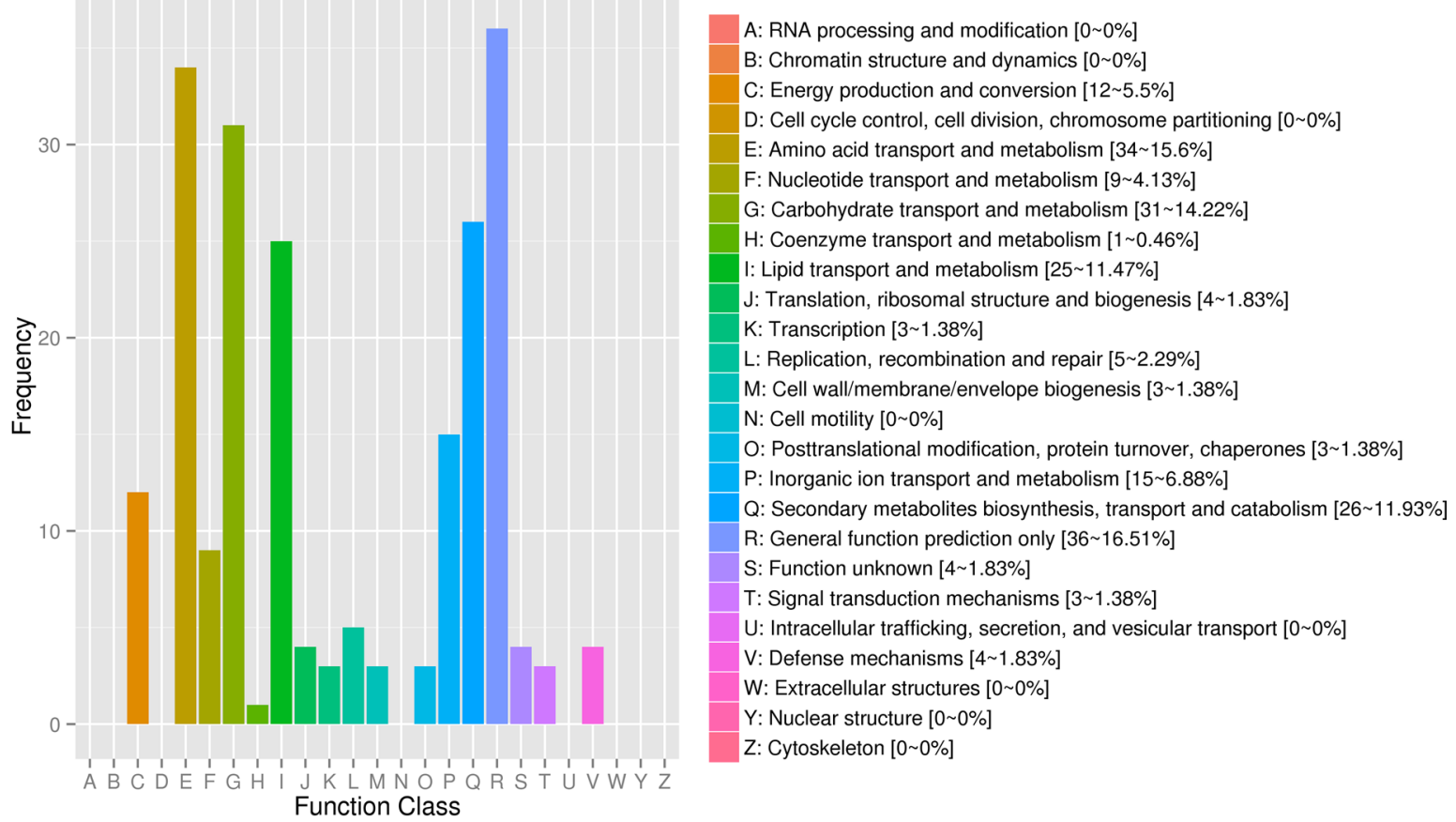

COG Function Classification of Consensus Sequence

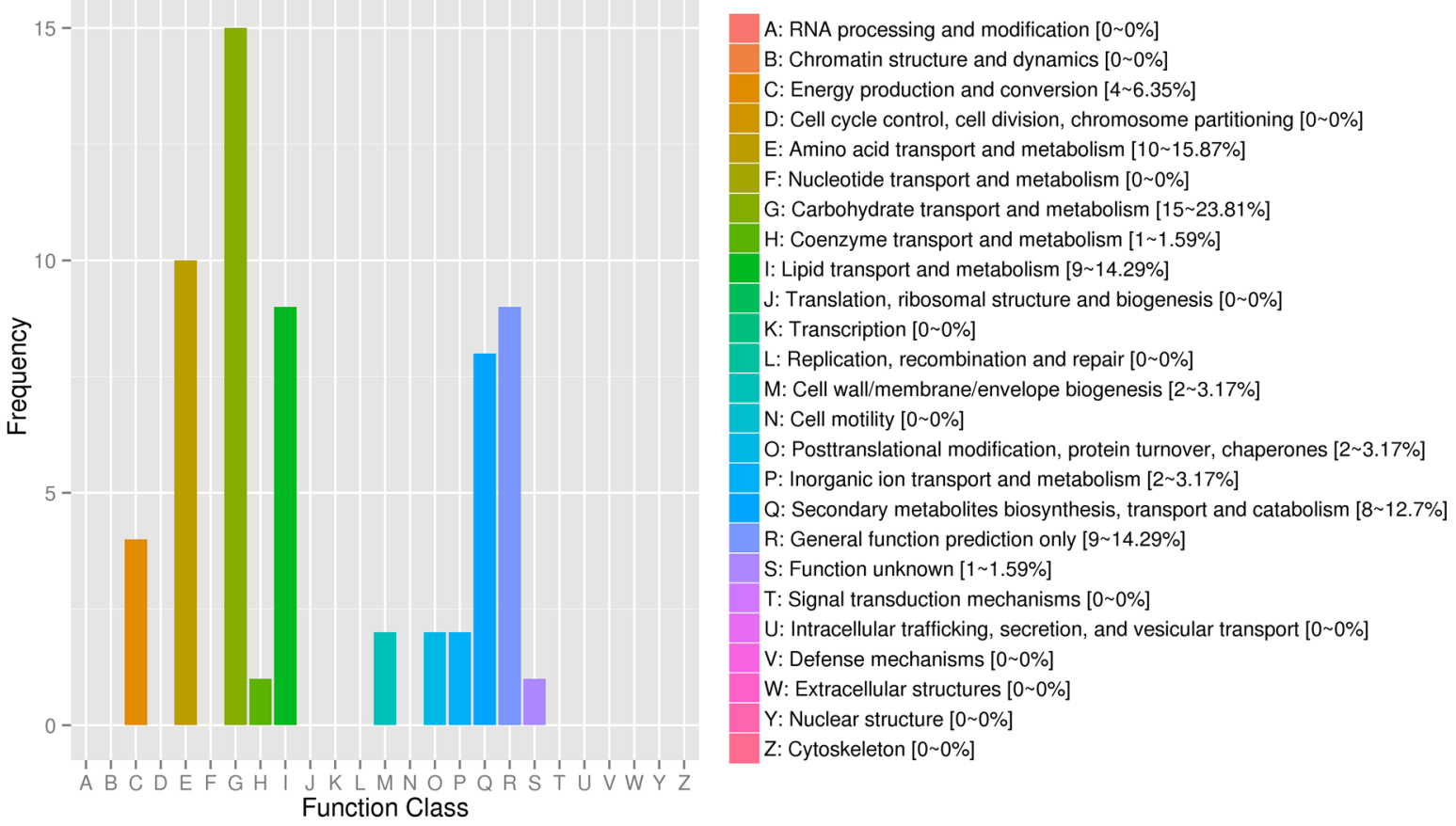

Figure 2. COG classification of putative proteins for S. paramamosain hepatopancreas transcriptome. (a) COG annotations of the DEGs at inter-molt stage and pre-molt stage. (b) COG annotations of the DEGs at pre-molt stage and post-molt stage. COG classification is mined here from https://www.ncbi.nlm.nih.gov/COG.

in iron storage, and plays a crucial role in iron metabolism. As some bacteria need to isolate iron, ferritin can protect organisms from bacterial infection by regulating free iron availability in the environment ${ }^{57}$.

Zinc protease belongs to the metal endopeptidases and is involved in a variety of physiological activities, including connective tissue remodeling and resection of nascent protein signal peptides ${ }^{56}$. A full-length ferritin cDNA clone has been isolated from the river prawn, Macrobrachium nipponense ${ }^{58}$, however, zinc protease in $S$. paramamosain has not yet been reported. In L. vannamei and the kuruma shrimp, Penaeus japonicas, mRNA of 
a

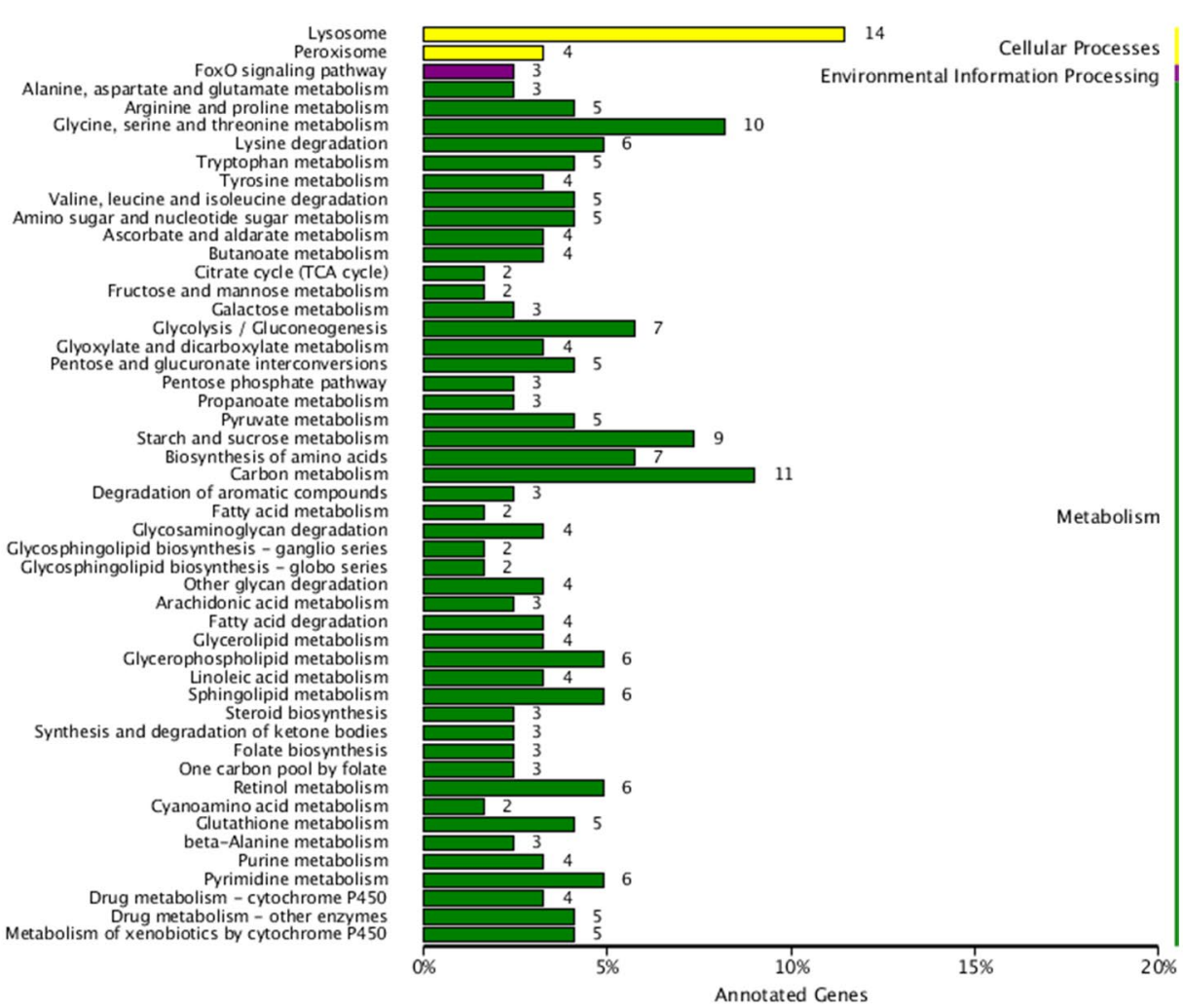

$\mathrm{b}$

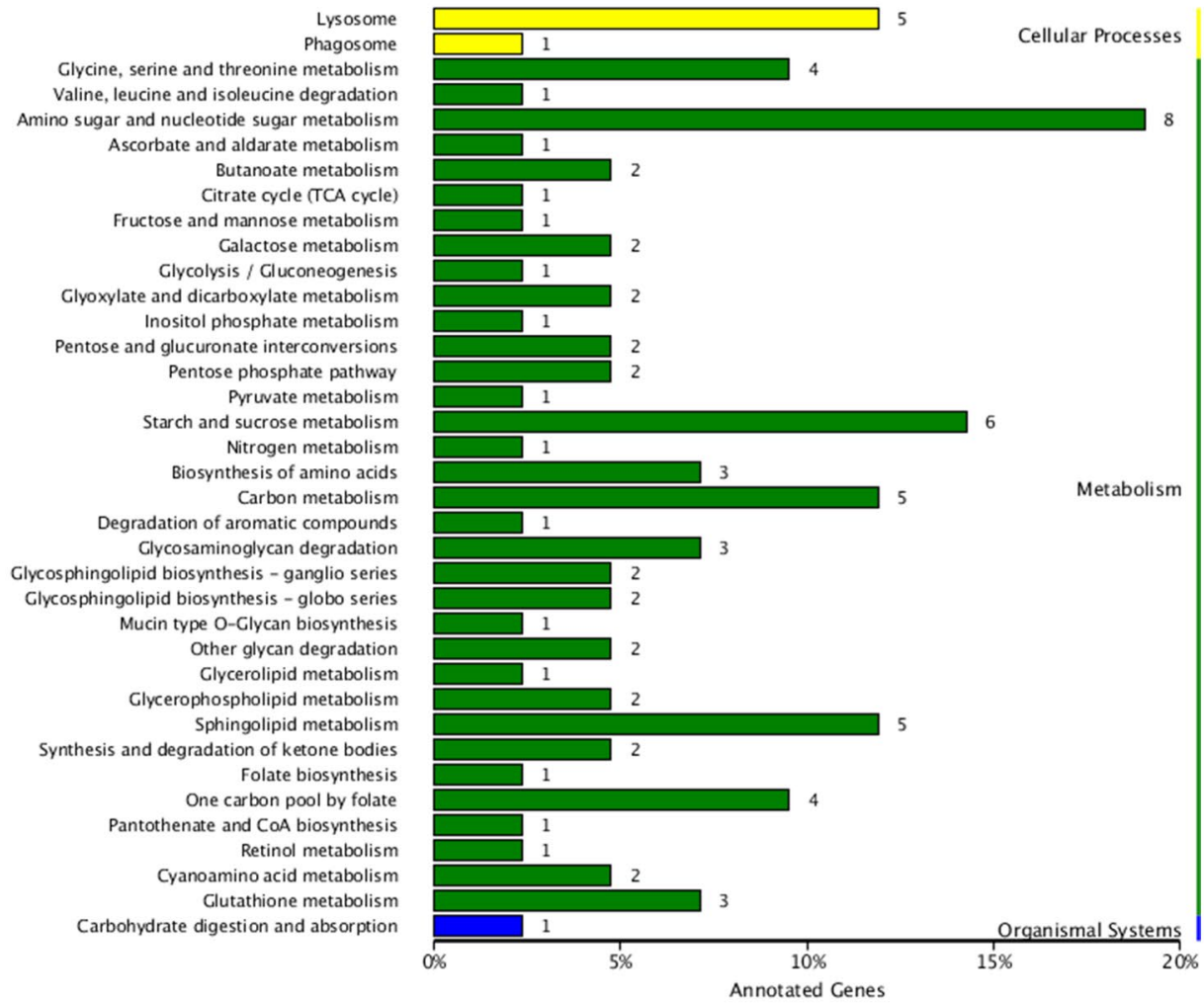

Figure 3. KEGG assignment of non-redundant unigenes for S. paramamosain hepatopancreas transcriptome. (a) KEGG pathways of the DEGs at inter-molt stage and pre-molt stage. (b) KEGG pathways of the DEGs at premolt stage and post-molt stage. KEGG assignment is mined here from https://www.kegg.jp/kegg/kegg1.html. The KEGG database has been reported previously ${ }^{92-94}$. 


\begin{tabular}{|c|c|c|c|c|c|c|}
\hline \multirow[b]{2}{*}{ Peptide families } & \multirow[b]{2}{*}{ Accession Num } & \multirow[b]{2}{*}{$\operatorname{Size}(\mathbf{b p}) /(\mathbf{a a})$} & \multicolumn{4}{|l|}{ Best blastx match } \\
\hline & & & Species name & E-value & Ident & Accession Num \\
\hline \multicolumn{7}{|l|}{ Antimicrobial peptides (AMPs) } \\
\hline Crustin antimicrobial peptide & c17146.graph_c0 & $557 / 185$ & Scylla paramamosain & $5 e-60$ & $100 \%$ & ABY20728.1 \\
\hline Sphyastatin & c34929.graph_c0 & $742 / 247$ & Scylla paramamosain & $2 \mathrm{e}-77$ & $100 \%$ & AFY10070.1 \\
\hline Lysozyme & c32013.graph_c0 & $942 / 314$ & Scylla paramamosain & $2 e-153$ & $99.55 \%$ & ADM33942.1 \\
\hline \multicolumn{7}{|l|}{ Inflammatory gene } \\
\hline Interleukin-16-like protein & c54350.graph_c0 & $6,041 / 2013$ & Eriocheir sinensis & 0.0 & $90 \%$ & AWM96383.1 \\
\hline \multicolumn{7}{|c|}{ Prophenol/phenol oxidase cascade } \\
\hline Trypsin-like serine proteinase & c23984.graph_c0 & $1,011 / 337$ & Eriocheir sinensis & $5 e-77$ & $52 \%$ & AKN46052.1 \\
\hline Trypsin-1-like & c32762.graph_c0 & $2,320 / 773$ & Acromyrmex echinatior & $3 e-37$ & $36 \%$ & XP_011063347.1 \\
\hline $\begin{array}{l}\text { Alpha2 macroglobulin isoform } \\
\text { 3, partial }\end{array}$ & c80987.graph_c0 & $463 / 154$ & Penaeus chinensis & $9 e-16$ & $59 \%$ & ACU31809.1 \\
\hline \multicolumn{7}{|l|}{ Toll signaling pathway } \\
\hline Toll-like receptor & c49018.graph_c0 & $4,265 / 1,421$ & Procambarus clarkii & 0.0 & $50.28 \%$ & AJE28352.1 \\
\hline \multicolumn{7}{|l|}{ Antioxidant enzymes } \\
\hline Catalase & c60548.graph_c0 & $3,312 / 1,104$ & Scylla paramamosain & 0.0 & $100 \%$ & ACX46120.1 \\
\hline Thioredoxin 2 & c29838.graph_c0 & $1674 / 558$ & Portunus trituberculatus & $5 e-72$ & $98 \%$ & AFE88627.1 \\
\hline \multicolumn{7}{|l|}{ Metal-binding proteins } \\
\hline Zinc proteinase Mpc1 & c69961.graph_c0 & $258 / 86$ & Litopenaeus vannamei & $2 \mathrm{e}-120$ & $79 \%$ & DQ398567.1 \\
\hline Ferritin & c42424.graph_c0 & $1,251 / 417$ & Scylla paramamosain & 1e-188 & $99 \%$ & ADM26622.1 \\
\hline \multicolumn{7}{|l|}{ Other immune factors } \\
\hline $\begin{array}{l}\text { Macrophage migration inhibi- } \\
\text { tory factor MIF1 }\end{array}$ & c37813.graph_c0 & $394 / 131$ & Scylla paramamosain & $7 e-73$ & $100 \%$ & AKT09427.1 \\
\hline Cathepsin L & c75535.graph_c0 & $369 / 123$ & Eriocheir sinensis & $3 e-40$ & $87 \%$ & ADO65978.1 \\
\hline C-type lectin & c10960.graph_c0 & $712 / 237$ & Eriocheir sinensis & $5 e-54$ & $50 \%$ & ADH43623.1 \\
\hline C-type lectin 2 & c76885.graph_c0 & $384 / 128$ & Scylla paramamosain & $4 \mathrm{e}-53$ & $63 \%$ & AEO92002.1 \\
\hline Hemocyanin subunit 1 & c27342.graph_c0 & $797 / 265$ & Scylla paramamosain & $8 \mathrm{e}-140$ & $77 \%$ & AKC96433.1 \\
\hline Hemocyanin subunit 3 & c94743.graph_c0 & $226 / 75$ & Scylla paramamosain & $2 e-44$ & $99 \%$ & AKC96431.1 \\
\hline
\end{tabular}

Table 3. Putative immune genes in the hepatopancreas transcriptome of S. paramamosain.

zinc proteinase and ferritin are more expressed in WSSV resistant individuals compared with susceptible ones ${ }^{59,60}$. These data support the role that these two metal binding proteins may guard against infection events that may accompany cuticle loss and regrowth during the molting process.

Other immune factors. In the present study, macrophage migration inhibitory factor (MIF), cathepsin L (CTSL), c-type lectins (CTLs) and hemocyanin were significantly up-regulated at the post-molt stage.

MIF is a regulator of the innate immune system, and plays a key role in host antimicrobial defense systems and stress responses ${ }^{61}$. Recently, it was regarded as a multi-functional protein, positioning MIF as a mediator during the inflammatory response to combat infection and in immunoinflammatory and autoimmune diseases ${ }^{62}$. At present, MIF homologs have been reported and studied in many crustacean species, such as S. paramamosain ${ }^{63}$, E. sinensis ${ }^{64}$, and Penaeus monodon ${ }^{65}$. In this study, MIF was significantly up-regulated at the post-molt stage, which may indicate that phagocytosis was promoted in S. paramamosain.

Cathepsin L (CTSL), a lysosomal cysteine protease, serves as a chemical barrier against microbial invasion in immune responses in vertebrates ${ }^{66,67}$. Cathepsin $L$ has been found in crustaceans, such as E. sinensis ${ }^{69}$ and $F$. chinensis $^{69}$, is responsible for lysing pathogenic bacteria and as a barrier against invading pathogens.

C-type lectins (CTLs) are a large superfamily of pattern-recognition receptors that play important roles in the immune system through identifying and binding to the conservative pathogen-associated molecular patterns (PAMPs) on pathogen surfaces ${ }^{70}$. As pattern recognition receptors, CTLs can identify and bind PAMPs on pathogen surfaces to promote the phagocytosis ${ }^{71,72}$. In bivalve and crustacean species, the hepatopancreas synthesizes lectins (such as CTLs and ficolins) in response to infection ${ }^{11,73,74}$.

Hemocyanin, was reported as a novel and important defense molecule of the non-specific innate immune system ${ }^{75-77}$. Studies have found that hemocyanin functions not only as an oxygen-carrying protein, but also as a phenoloxidase-like enzyme ${ }^{78}$, and has antiviral activity, through its enzymatic cleavage, produces AMPs against a variety of viruses ${ }^{79-81}$. Agglutination activities against bacteria have also been observed as an antimicrobial strategy ${ }^{82,83}$.

To our knowledge, this is the first transcriptome analysis of the change of immune related genes in the hepatopancreas during the molt cycle in S. paramamosain (Fig. 6). Although these genes are usually multifunctional, they are significantly up-regulated at the post-molt stage and inter-molt stage revealing a potential role of the hepatopancreas in protecting crabs susceptible to infection. 
Post-molt stage Inter-molt stage Pre-molt stage

\begin{tabular}{|c|c|c|c|}
\hline $101.86 \pm 54.58$ & $77.31 \pm 13.67$ & $3.77 \pm 0.99$ & Crustin antimicrobial peptide \\
\hline $316.11 \pm 129.47$ & $305.08 \pm 97.52$ & $44.30 \pm 23.92$ & Sphyastatin \\
\hline $79.46 \pm 9.45$ & $101.54 \pm 24.31$ & $50.98 \pm 26.20$ & Lysozyme \\
\hline $62.96 \pm 12.04$ & $40.09 \pm 3.94$ & $25.61 \pm 8.19$ & Interleukin-16-like protein \\
\hline $66.14 \pm 20.86$ & $39.55 \pm 3.61$ & $2.39 \pm 0.37$ & Trypsin-like serine proteinase \\
\hline $13.39 \pm 3.69$ & $25.45 \pm 6.96$ & $3.82 \pm 1.46$ & Trypsin-1-like \\
\hline $3.81 \pm 2.02$ & $13.64 \pm 4.32$ & $0.34 \pm 0.25$ & Alpha2 macroglobulin isoform 3 , partial \\
\hline $154.95 \pm 19.49$ & $121.22 \pm 30.34$ & $39.37 \pm 10.51$ & Toll-like receptor \\
\hline $1473.88 \pm 344.63$ & $1092.74 \pm 20.30$ & $88.17 \pm 18.87$ & Catalase \\
\hline $436.90 \pm 31.38$ & $250.49 \pm 29.36$ & $22.30 \pm 2.15$ & Thioredoxin 2 \\
\hline $173.42 \pm 51.94$ & $96.33 \pm 32.66$ & $\mathbf{0} \pm \mathbf{0}$ & Zinc proteinase Mpc1 \\
\hline $46239.69 \pm 12834.47$ & $58357.96 \pm 10053.78$ & $10726.15 \pm 821.06$ & Ferritin \\
\hline $95.75 \pm 37.46$ & $75.31 \pm 18.80$ & $4.76 \pm 1.06$ & Macrophage migration inhibitory factor MIF1 \\
\hline $916.22 \pm 366.81$ & $1448.31 \pm 199.38$ & $5.48 \pm 2.66$ & Cathepsin $\mathbf{L}$ \\
\hline $3557.48 \pm 424.59$ & $1993.30 \pm 280.40$ & $96.79 \pm 24.07$ & C-type lectin \\
\hline $1384.39 \pm 422.61$ & $1318.07 \pm 307.85$ & $17.48713 \pm 1.74$ & C-type lectin 2 \\
\hline $340.43 \pm 72.06$ & $808.18 \pm 159.14$ & $27.54 \pm 14.10$ & Hemocyanin subunit 1 \\
\hline $297.45 \pm 86.46$ & $1359.12 \pm 651.08$ & $3.96 \pm 1.95$ & Hemocyanin subunit 3 \\
\hline
\end{tabular}

Figure 4. Heatmap showing the abundance of expression of the immune genes. The values in the figure indicate FPKM (fragments per kilobase million). Data are shown as mean \pm SEM.

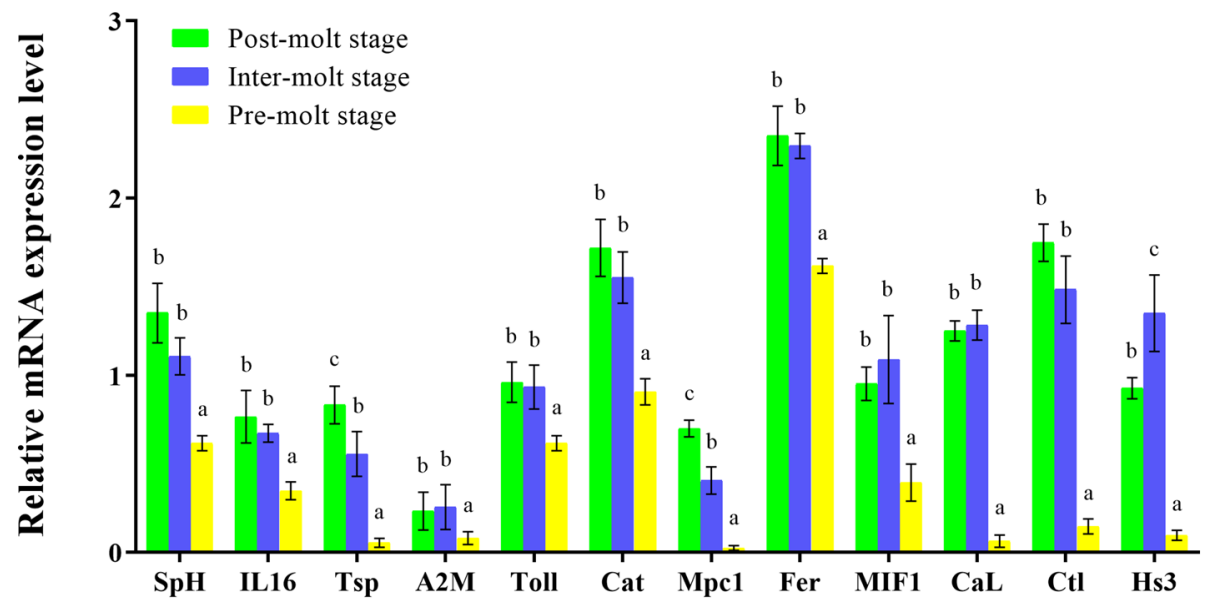

Figure 5. The DEGs of the hepatopancreas at three stages in S. paramamosain. SpH Sphyastatin, IL16 Interleukin-16-like protein, Tsp Trypsin-like serine proteinase, A2M Alpha2 macroglobulin isoform 3, Toll Toll-like receptor, Cat Catalase, Mpc1 Zinc proteinase Mpc1, Fer Ferritin, MIF1 Macrophage migration inhibitory factor, Cal Cathepsin L, Ctl C-type lectin, $H s 3$ Hemocyanin subunit 3, $\beta$-actin was used as reference gene. Columns with different superscript letters indicate the significant difference when compared by ANOVA $(\mathrm{P}<0.05)$. 


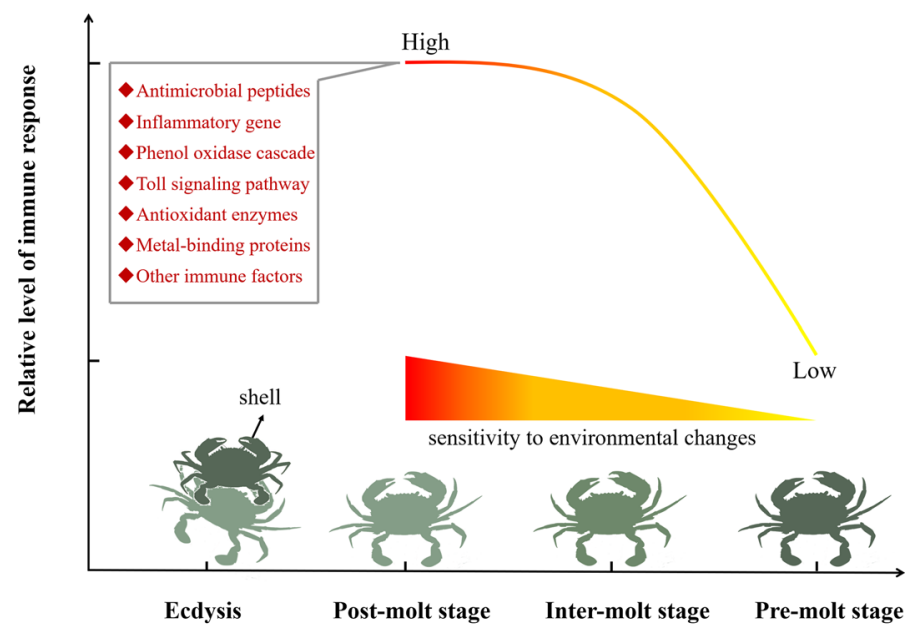

Figure 6. Immune molecular events of $S$. paramamosain during the molting process. This schematic depicts the level of immune response in relation to the environmental sensitivity of the molt cycle. The rhombus represents the molecular events of change; the $\mathrm{x}$-axis represents the stage of molting; the $\mathrm{y}$-axis represents the level of hepatopancreas immune changes.

\section{Materials and methods}

Ethics statement. All animals used in this study have been approved by the Institutional Animal Care and Use Committee of Xiamen University and experimental protocols carried out in strict accordance with the guidelines of the university.

Sample collection. Mud crabs (S. paramamosain), averaging $7.9 \pm 0.4 \mathrm{~cm}$ in carapace width and $100.2 \pm 8.1 \mathrm{~g}$ in body weight, were collected from the aquafarm in Xiamen city, Fujian Province, China, and then transported to laboratory. They were reared in tanks (temperature: $26 \pm 0.5^{\circ} \mathrm{C}$ ), fed with shrimp meat, and the water was changed every day. Mud crabs at three molt stages were sampled according to the previous study ${ }^{16}$. Post-molt stage: the mud crab just molted for 1-2 days, it was very thin, only dorsal carapace edge hard,Inter-molt stage: the dominant phase of the inter-molt period, the mud crab was full of meat, the exoskeleton was consolidated and hardened,Pre-molt stage: the fourth phase of the pre-molt period, namely double shell crab, pleural suture cracks between the carapace and the abdomen. Three individual crabs at each molt stage were sampled, placed on ice for anesthetization and then dissected for the hepatopancreas for RNA isolation. Three biological replicates were performed per tissue at each molt stage, for a total of 9 samples.

RNA isolation and cDNA library preparation. Total RNA was extracted from each tissue using TRIzol RNA isolation reagent (Invitrogen) according to the manufacturer's instructions. The RNA quantity and integrity were determined with an Aglient 2100 Bioanalyzer and a Qubit 2.0 Fluorometer. Magnetic beads with oligo (dT) were used to separate Poly-(A)-containing mRNA. Fragmentation buffer was added to randomly interrupt the mRNA into short fragments. The mRNA fragments were used as templates to synthesize the first-strand cDNA with random hexamer-primers, then add buffer, dNTPs, RNase $\mathrm{H}$, and DNA polymerase I to synthesize the second-stranded cDNA, and further purified using Agencourt AMPure XP beads (Beckman Coulter). Next, double-stranded cDNA fragment ends were repaired, adding of poly (A) and ligation of adapters. The fragment size was selected using Agencourt AMPure XP beads. The PCR amplification to create the final cDNA library, and sequenced using the Illumina HiSeq2500.

Cleaning and de novo assembly of sequencing reads. The assembles to compiled data from all 9 samples were assembled together for assembly, as this method is often more accurate and comprehensive for samples from the same species without a genome-wide reference ${ }^{84}$. The Trinity software first breaks the sequencing Reads into shorter fragments (K-mer), then extends the small fragments into longer fragments (Contig), and uses the overlap between the fragments to get the fragment. Finally, using the De Bruijn map method and sequencing Read information, the transcript sequences are separately identified in each fragment set ${ }^{85}$. The resulting clean readings were archived at the National Center for Biotechnology Information (NCBI) Sequence Read Archive, accession number is PRJNA617953.

Transcriptome functional annotation. Assembled transcriptomes were annotated using BLASTX against the Swiss-Prot, GO, NCBI-NR, COG, KEGG, with a cutoff E-value smaller than 1e-5. Analysis of Unigene results in KEGG Orthology using KOBAS 2.0 software $^{86}$. HMMER software compares the predicted amino acid sequence with the Pfam database to obtain Unigene annotation information, with a cut off E-value smaller than $1 \mathrm{e}-10$. TransDecoder software is based on the open reading frame (ORF), the alignment of the amino acid 


\begin{tabular}{|c|c|}
\hline Name & Sequence $\left(5^{\prime} \rightarrow 3^{\prime}\right)$ \\
\hline$S p H-F$ & GCACCAAGCCCTTGATCTCC \\
\hline$S p H-R$ & GTTGCTGCGGGTGAAGGAAT \\
\hline IL16-F & CTCGCAGGGAAAGCAATGGT \\
\hline IL16- $R$ & GGCTGTTGGACGAAGACTGG \\
\hline$T s p-F$ & CCСTTCTGTTGGCAGTGCTT \\
\hline$T s p-R$ & GCTTGGTCTGCTCCACAGTC \\
\hline$A 2 M-F$ & GAGGCTGGTAAGGGCTGACT \\
\hline$A 2 M-R$ & GAGAATGTGTGCGTGCGGAT \\
\hline Toll-R & GCTCCAGGAAGGTGTTGGTG \\
\hline Toll-F & AGGAAGCGCAGTTTCTTGGG \\
\hline Cat-F & TGGGAGCCAACTACCACCAA \\
\hline Cat-R & GCAGTCCATAGGGCCAGAGA \\
\hline$M p c 1-F$ & GGCACGTACTCCTTCTCCGT \\
\hline$M p c 1-R$ & TGTGTGCAGTTTCGTGTTGC \\
\hline Fer-F & GCCCTACCACGCCATTGATT \\
\hline Fer- $R$ & GATGGAGGCCTCACACTCCT \\
\hline MIF1-F & CCTGTGTGTGAGCTGCATGT \\
\hline MIF1-R & GGCTGCAAGGCTGAGAAGTT \\
\hline$C a L-F$ & GTACCGTAACCCACCGCAAG \\
\hline$C a L-R$ & TCCCAGCCCACTTTCCACTT \\
\hline$C t l-F$ & GTCTGTGGCAAATGCAGGGT \\
\hline$C t l-R$ & AGATTCCCGTCGTGACCACT \\
\hline$H s 3-F$ & CGACCCACATGGCAAGTTCA \\
\hline$H s 3-R$ & CGTGTAGCGGTCTCGAAGTG \\
\hline$\beta$-actin-F & GAGCGAGAAATCGTTCGTGAC \\
\hline$\beta$-actin-R & GGAAGGAAGGCTGGAAGAGAG \\
\hline
\end{tabular}

Table 4. The primers used in qRT-PCR.

sequence with protein domain sequence in Pfam (Protein family) database and other information, which can identify reliable potential coding sequence (CDS) from the transcript sequences. The Reads sequenced from each sample were mapped back to Unigene database using Bowtie ${ }^{87}$, and the expression level was estimated according to the comparison results combined with RSEM 88 (RNA-Seq by Expectation Maximization). The fragments per kilobase of transcript, per million fragments sequenced (FPKM) value indicates the expression abundance corresponding to each unigene.

Differential expression analysis. Pearson's Correlation Coefficient ( $r$ ) serves as an evaluation index of biological repeat correlation ${ }^{89}$. $\mathrm{DESeq}^{90}$ was used to identify the differentially expressed genes (DEGs). To ensure high quality of DEGs, Benjamini-Hochberg-corrected $P$ values ( $q$ values) were calculated for one multiple hypothesis testing false discovery rate $(\mathrm{FDR}<0.01)$ and fold change $(\mathrm{FC} \leq 2)$ adopted as the key indicator for DEGs. The expression levels of up-regulated or down-regulated DEGs were annotated in the GO annotation database were enrichment analyzed using the topGO software ${ }^{91}$. COG database can perform orthologous classification of gene products and KEGG database helps to further interpret the function of gene. The Enrichment Factor was used to analyze the enrichment of pathway, and the Fisher's exact test method was used to calculate the enrichment significance.

Gene expression validation. To validate and quantify the transcriptome data, genes identified in the DEGs were selected and then quantified using quantitative real-time PCR (qRT-PCR). Primers were designed using Primer 5.0 Tool (Premier, Canada). The stable housekeeping gene $\beta$-actin was used as an internal control (Table 4). qRT-PCR using a 7,500 Fast Real-Time PCR system (Applied Biosystems) was performed with the following thermal profile: One cycle at $95^{\circ} \mathrm{C}$ for $30 \mathrm{~s}$, followed by 40 cycles of $95^{\circ} \mathrm{C}$ for $5 \mathrm{~s}, 58^{\circ} \mathrm{C} \mathrm{for} 30 \mathrm{~s}$, and $72{ }^{\circ} \mathrm{C}$ for $30 \mathrm{~s}$. The qRT-PCR was carried out in triplicate for each sample, and five mud crabs were analyzed in each group. Expression levels of different genes were estimated using the $2^{-\Delta \Delta C t}$ method. Statistical significance $(\mathrm{P}<0.05)$ was determined using Duncan's multiple range tests and one-way ANOVA under SPSS 18.0. 


\section{References}

1. Dittel, A. I. \& Epifanio, C. E. Invasion biology of the Chinese mitten crab Eriochier sinensis: A brief review. J. Exp. Mar. Biol. Ecol. 374, 79-92. https://doi.org/10.1016/j.jembe.2009.04.012 (2009).

2. Guo, Y. R., Gu, S. Q., Wang, X. C., Zhao, L. M. \& Zheng, J. Y. Comparison of fatty acid and amino acid profiles of steamed Chinese mitten crab. Fish Sci. 80, 621-633 (2014).

3. Tian, Z. \& Kang, X. The molt stages and the hepatopancreas contents of lipids, glycogen and selected inorganic elements during the molt cycle of the Chinese mitten crab Eriocheir sinensis. Fish Sci. 78, 67-74 (2012).

4. Chang, E. S. \& Mykles, D. L. Regulation of crustacean molting: A review and our perspectives. Gen. Comp. Endocrinol. 172, 323-330. https://doi.org/10.1016/j.ygcen.2011.04.003 (2011).

5. Chang, E. S. Physiological and biochemical changes during the molt cycle in decapod crustaceans: An overview. J. Exp. Mar. Biol. Ecol. 193, 1-14. https://doi.org/10.1016/0022-0981(95)00106-9 (1995).

6. Huynh, T. T., Silvestre, F., Nguyen, T. P. \& Kestemont, P. Effects of pesticides and antibiotics on penaeid shrimp with special emphases on behavioral and biomarker responses. Environ. Toxicol. Chem. 29, 929-938. https://doi.org/10.1002/etc.99 (2010).

7. Corteel, M. et al. Molt stage and cuticle damage influence white spot syndrome virus immersion infection in penaeid shrimp. Vet. Microbiol. 137, 209-216. https://doi.org/10.1016/j.vetmic.2009.01.018 (2009).

8. Tumburu, L., Shepard, E. F., Strand, A. E. \& Browdy, C. L. Effects of endosulfan exposure and Taura syndrome virus infection on the survival and molting of the marine penaeid shrimp, Litopenaeus vannamei. Chemosphere 86, 912-918. https://doi.org/10.1016/j. chemosphere.2011.10.057 (2012).

9. Wang, L., Yan, B., Liu, N., Li, Y. \& Wang, Q. Effects of cadmium on glutathione synthesis in hepatopancreas of freshwater crab, Sinopotamon yangtsekiense. Chemosphere 74, 51-56. https://doi.org/10.1016/j.chemosphere.2008.09.025 (2008).

10. Soonthornchai, W. et al. Expression of immune-related genes in the digestive organ of shrimp, Penaeus monodon, after an oral infection by Vibrio harveyi. Dev. Comp. Immunol. 34, 19-28. https://doi.org/10.1016/j.dci.2009.07.007 (2010).

11. Sun, S. M. et al. Identification of differentially expressed genes in hepatopancreas of oriental river prawn, Macrobrachium nipponense exposed to environmental hypoxia. Gene 534, 298-306. https://doi.org/10.1016/j.gene.2013.10.036 (2014).

12. Li, X., Cui, Z., Liu, Y., Song, C. \& Shi, G. Transcriptome analysis and discovery of genes involved in immune pathways from hepatopancreas of microbial challenged mitten crab Eriocheir sinensis. PLoS ONE 8, e68233. https://doi.org/10.1371/journal.pone.00682 33 (2013).

13. Wei, Y. J. et al. A possible role of crustacean cardioactive peptide in regulating immune response in hepatopancreas in mud crab. Front. Immunol. 11, 711. https://doi.org/10.3339/fimmu.2020.00711 (2020).

14. Huang, S. et al. Transcriptomic variation of hepatopancreas reveals the energy metabolism and biological processes associated with molting in Chinese mitten crab, Eriocheir sinensis. Sci. Rep. 5, 14015. https://doi.org/10.1038/srep14015 (2015).

15. Le Vay, L. Ecology and management of mud crab Scylla spp. Asian Fish Sci. 14, 101-112 (2001).

16. Jiang, Q. et al. Transcriptome profiling of claw muscle of the mud crab (Scylla paramamosain) at different fattening stages. PLoS ONE 12, e0188067. https://doi.org/10.1371/journal.pone.0188067 (2017).

17. Ashburner, M. et al. Gene ontology: Tool for the unification of biology. The gene ontology consortium. Nat. Genet. 25, 25-29. https://doi.org/10.1038/75556 (2000).

18. Tatusov, R. L., Galperin, M. Y., Natale, D. A. \& Koonin, E. V. The COG database: A tool for genome-scale analysis of protein functions and evolution. Nucleic Acids Res 28, 33-36. https://doi.org/10.1093/nar/28.1.33 (2000).

19. Kanehisa, M., Goto, S., Kawashima, S., Okuno, Y. \& Hattori, M. The KEGG resource for deciphering the genome. Nucleic Acids Res 32, D277-280. https://doi.org/10.1093/nar/gkh063 (2004).

20. Conesa, A. et al. Blast2GO: A universal tool for annotation, visualization and analysis in functional genomics research. Bioinformatics 21, 3674-3676. https://doi.org/10.1093/bioinformatics/bti610 (2005).

21. Song, L. et al. Characterization of a chitinase-1 gene (PtCht-1) from a marine crab Portunus trituberculatus and its response to immune stress. Gene https://doi.org/10.1016/j.gene.2020.144523 (2020).

22. An, S. et al. Insect neuropeptide bursicon homodimers induce innate immune and stress genes during molting by activating the NF-kappaB transcription factor Relish. PLoS ONE 7, e34510. https://doi.org/10.1371/journal.pone.0034510 (2012).

23. Smith, V. J., Fernandes, J. M., Kemp, G. D. \& Hauton, C. Crustins: Enigmatic WAP domain-containing antibacterial proteins from crustaceans. Dev. Comp. Immunol. 32, 758-772. https://doi.org/10.1016/j.dci.2007.12.002 (2008).

24. Relf, J. M., Chisholm, J. R., Kemp, G. D. \& Smith, V. J. Purification and characterization of a cysteine-rich 11.5-kDa antibacterial protein from the granular haemocytes of the shore crab, Carcinus maenas. Eur. J. Biochem. 264, 350-357. https://doi.org/10.104 6/j.1432-1327.1999.00607.x (1999).

25. Shan, Z. et al. The new antimicrobial peptide SpHyastatin from the mud crab Scylla paramamosain with multiple antimicrobial mechanisms and high effect on bacterial infection. Front. Microbiol. 7, 1140. https://doi.org/10.3389/fmicb.2016.01140 (2016).

26. Chen, F. Y., Liu, H. P., Bo, J., Ren, H. L. \& Wang, K. J. Identification of genes differentially expressed in hemocytes of Scylla paramamosain in response to lipopolysaccharide. Fish Shellfish Immunol. 28, 167-177. https://doi.org/10.1016/j.fsi.2009.10.017 (2010).

27. Shan, Z. G. et al. In vivo activity and the transcriptional regulatory mechanism of the antimicrobial peptide SpHyastatin in Scylla paramamosain. Fish Shellfish Immunol. 59, 155-165. https://doi.org/10.1016/j.fsi.2016.10.023 (2016).

28. Callewaert, L. \& Michiels, C. W. Lysozymes in the animal kingdom. J. Biosci. 35, 127-160 (2010).

29. Loker, E. S., Adema, C. M., Zhang, S. M. \& Kepler, T. B. Invertebrate immune systems-not homogeneous, not simple, not well understood. Immunol. Rev. 198, 10-24 (2004).

30. Zhou, J. et al. Newly identified invertebrate-type lysozyme (Splys-i) in mud crab (Scylla paramamosain) exhibiting muramidasedeficient antimicrobial activity. Dev. Comp. Immunol. 74, 154-166. https://doi.org/10.1016/j.dci.2017.04.017 (2017).

31. Cruikshank, W. \& Center, D. M. Modulation of lymphocyte migration by human lymphokines. II. Purification of a lymphotactic factor (LCF). J. Immunol. 128, 2569-2574 (1982).

32. Conti, P. et al. Interleukin-16 network in inflammation and allergy. Allergy Asthma Proc 23, 103-108 (2002).

33. Croq, F. et al. A homologous form of human interleukin 16 is implicated in microglia recruitment following nervous system injury in leech Hirudo medicinalis. Glia 58, 1649-1662. https://doi.org/10.1002/glia.21036 (2010).

34. Richmond, J., Finkel, M., Studwell, A., Little, F. \& Cruikshank, W. Introduction of pro-interleukin-16 inhibits T-lymphoblastic leukemia growth in mice. J. Cancer Res. Clin. Oncol. 137, 1581-1585. https://doi.org/10.1007/s00432-011-1017-x (2011).

35. Gu, W. B. et al. Identification and characterization of pro-interleukin-16 from mud crab Scylla paramamosain: the first evidence of proinflammatory cytokine in crab species. Fish Shellfish Immunol. 70, 701-709. https://doi.org/10.1016/j.fsi.2017.09.057 (2017).

36. Shi, X. Z., Zhao, X. F. \& Wang, J. X. Molecular cloning and expression analysis of chymotrypsin-like serine protease from the Chinese shrimp, Fenneropenaeus chinensis. Fish Shellfish Immunol. 25, 589-597. https://doi.org/10.1016/j.fsi.2008.07.011 (2008).

37. Fang, D. A. et al. Molecular cloning and expression analysis of chymotrypsin-like serine protease from the redclaw crayfish (Cherax quadricarinatus): A possible role in the junior and adult innate immune systems. Fish Shellfish Immunol. 34, 1546-1552. https:// doi.org/10.1016/j.fsi.2013.03.360 (2013).

38. Zhang, Q. X., Liu, H. P., Chen, R. Y., Shen, K. L. \& Wang, K. J. Identification of a serine proteinase homolog (Sp-SPH) involved in immune defense in the mud crab Scylla paramamosain. PLoS ONE 8, e63787. https://doi.org/10.1371/journal.pone.0063787 (2013).

39. Armstrong, P. B. The contribution of proteinase inhibitors to immune defense. Trends Immunol. 22, 47-52 (2001). 
40. Kanost, M. R. Serine proteinase inhibitors in arthropod immunity. Dev. Comp. Immunol. 23, 291-301 (1999).

41. Rupprecht, M., Birner, K., Gruber, H. \& Mulder, R. H. Humoral immunity in long-lived arthropods. J. Insect. Physiol. 42, 53-64 (1996).

42. Tauszig, S., Jouanguy, E., Hoffmann, J. A. \& Imler, J. L. Toll-related receptors and the control of antimicrobial peptide expression in Drosophila. Proc. Natl. Acad. Sci. USA 97, 10520-10525. https://doi.org/10.1073/pnas.180130797 (2000).

43. Beutler, B. Inferences, questions and possibilities in toll-like receptor signalling. Nature 430, 257-263. https://doi.org/10.1038/ nature02761 (2004).

44. Mekata, T., Kono, T., Yoshida, T., Sakai, M. \& Itami, T. Identification of cDNA encoding toll receptor, MjToll gene from kuruma shrimp Marsupenaeus japonicus. Fish Shellfish Immunol. 24, 122-133. https://doi.org/10.1016/j.fsi.2007.10.006 (2008).

45. West, A. P., Koblansky, A. A. \& Ghosh, S. Recognition and signaling by toll-like receptors. Annu. Rev. Cell Dev. Biol. 22, $409-437$. https://doi.org/10.1146/annurev.cellbio.21.122303.115827 (2006).

46. Yang, C. et al. A toll receptor from Chinese shrimp Fenneropenaeus chinensis is responsive to Vibrio anguillarum infection. Fish Shellfish Immunol. 24, 564-574. https://doi.org/10.1016/j.fsi.2007.12.012 (2008).

47. Yang, L. S. et al. A toll receptor in shrimp. Mol. Immunol. 44, 1999-2008. https://doi.org/10.1016/j.molimm.2006.09.021 (2007).

48. Chen, Y. et al. SpToll1 and SpToll2 modulate the expression of antimicrobial peptides in Scylla paramamosain. Dev. Comp. Immunol. 87, 124-136. https://doi.org/10.1016/j.dci.2018.06.008 (2018).

49. Deepika, A., Sreedharan, K., Paria, A., Makesh, M. \& Rajendran, K. V. Toll-pathway in tiger shrimp (Penaeus monodon) responds to white spot syndrome virus infection: Evidence through molecular characterisation and expression profiles of MyD88, TRAF6 and TLR genes. Fish Shellfish Immunol. 41, 441-454. https://doi.org/10.1016/j.fsi.2014.09.026 (2014).

50. Zhou, Y. L. et al. Identification and functional analysis of immune deficiency (IMD) from Scylla paramamosain: The first evidence of IMD signaling pathway involved in immune defense against bacterial infection in crab species. Fish Shellfish Immunol. 81, 150-160. https://doi.org/10.1016/j.fsi.2018.07.016 (2018).

51. Liu, H. P. et al. Antioxidant enzymes from the crab Scylla paramamosain: gene cloning and gene/protein expression profiles against LPS challenge. Fish Shellfish Immunol. 28, 862-871. https://doi.org/10.1016/j.fsi.2010.02.008 (2010).

52. Wang, M. et al. The molecular characterization of a catalase from Chinese mitten crab Eriocheir sinensis. Int. J. Immunogenet. 40, 230-240. https://doi.org/10.1111/iji.12019(2013).

53. Cunningham, G. M. et al. The paradoxical role of thioredoxin on oxidative stress and aging. Arch. Biochem. Biophys. 576, 32-38. https://doi.org/10.1016/j.abb.2015.02.025 (2015).

54. Koharyova, M. \& Kollarova, M. Thioredoxin system-a novel therapeutic target. Gen. Physiol. Biophys. 34, 221-233. https://doi. org/10.4149/gpb_2015006 (2015).

55. Hu, J. et al. Second thioredoxin from the mud crab Scylla paramamosain: cDNA cloning and mRNA expression analysis. J. Crustacean Biol. 33, 681-690 (2013).

56. Webster, N. L. \& Crowe, S. M. Matrix metalloproteinases, their production by monocytes and macrophages and their potential role in HIV-related diseases. J. Leukocyte Biol. 80, 1052-1066 (2006).

57. Chen, X. X. et al. A CqFerritin protein inhibits white spot syndrome virus infection via regulating iron ions in red claw crayfish Cherax quadricarinatus. Dev. Comp. Immunol. 82, 104-112. https://doi.org/10.1016/j.dci.2018.01.008 (2018).

58. Zhang, D. et al. Isolation and characterization of a ferritin cDNA from the mud crab Scylla paramamosain. J. Crustacean Biol. 31, 345-351 (2011).

59. Pan, D., He, N. H., Yang, Z. Y., Liu, H. P. \& Xu, X. Differential gene expression profile in hepatopancreas of WSSV-resistant shrimp (Penaeus japonicus) by suppression subtractive hybridization. Dev. Comp. Immunol. 29, 103-112 (2005).

60. Zhao, Z. Y. et al. Profiling of differentially expressed genes in hepatopancreas of white spot syndrome virus-resistant shrimp (Litopenaeus vannamei) by suppression subtractive hybridisation. Fish Shellfish Immunol. 22, 520-534 (2007).

61. George, M. \& Vaughan, J. H. In vitro cell migration as a model for delayed hypersensitivity. Proc. Soc. Exp. Biol. Med. 111, 514-521. https://doi.org/10.3181/00379727-111-27841 (1962).

62. Calandra, T. \& Roger, T. Macrophage migration inhibitory factor: A regulator of innate immunity. Nat. Rev. Immunol. 3, 791-800. https://doi.org/10.1038/nri1200 (2003).

63. Fang, Y. et al. Macrophage migration inhibitory factor in mud crab Scylla paramamosain: Molecular cloning, expression profiles in various tissues and under Vibrio challenge. Mol. Biol. 47, 625-633 (2013).

64. Li, W. W. et al. Molecular cloning, characterization and expression analysis of macrophage migration inhibitory protein (MIF) in Chinese mitten crab Eriocheir sinensis. Fish Shellfish Immunol. 30, 324-329. https://doi.org/10.1016/j.fsi.2010.11.008 (2011).

65. Xie, B. et al. Cloning, characterization, and expression of the macrophage migration inhibitory factor gene from the black tiger shrimp (Penaeus monodon). Fish Shellfish Immunol. 56, 489-495. https://doi.org/10.1016/j.fsi.2016.08.008 (2016).

66. Biroc, S. L. et al. Cysteine protease activity is up-regulated in inflamed ankle joints of rats with adjuvant-induced arthritis and decreases with in vivo administration of a vinyl sulfone cysteine protease inhibitor. Arthritis Rheum. 44, 703-711 (2001).

67. Gelb, B. D., Shi, G. P., Chapman, H. A. \& Desnick, R. J. Pycnodysostosis, a lysosomal disease caused by cathepsin K deficiency. Science 273, 1236-1238. https://doi.org/10.1126/science.273.5279.1236 (1996).

68. Li, W. W. et al. Molecular cloning, characterization, expression and activity analysis of cathepsin L in Chinese mitten crab, Eriocheir sinensis. Fish Shellfish Immunol 29, 1010-1018 (2010).

69. Le Boulay, C., Sellos, D. \& Van Wormhoudt, A. Cathepsin L gene organization in crustaceans. Gene 218, 77-84 (1998).

70. Wang, H. et al. Cloning and characterization of a novel C-type lectin from Zhikong scallop Chlamys farreri. Mol. Immunol. 44, 722-731 (2007).

71. Yamaura, K., Takahashi, K. G. \& Suzuki, T. Identification and tissue expression analysis of C-type lectin and galectin in the Pacific oyster Crassostrea gigas. Comp. Biochem. Phys. B 149, 168-175 (2008).

72. Yang, J. L. et al. C-type lectin in chlamys farreri (CfLec-1) mediating immune recognition and opsonization. PLoS ONE 6, 1 (2011).

73. Huang, M. M. et al. A C-type lectin (AiCTL-3) from bay scallop Argopecten irradians with mannose/galactose binding ability to bind various bacteria. Gene 531, 31-38 (2013).

74. Zhang, X. W. et al. Cloning and characterization of two different ficolins from the giant freshwater prawn Macrobrachium rosenbergii. Dev. Comp. Immunol. 44, 359-369. https://doi.org/10.1016/j.dci.2014.01.009 (2014).

75. Decker, H. et al. Minireview: Recent progress in hemocyanin research. Integr. Comp. Biol. 47, 631-644 (2007).

76. Decker, H. \& Jaenicke, E. Recent findings on phenoloxidase activity and antimicrobial activity of hemocyanins. Dev. Comp. Immunol. 28, 673-687 (2004).

77. Terwilliger, N. B. Hemocyanins and the immune response: defense against the dark arts. Integr. Comp. Biol.. 47, 662-665. https:// doi.org/10.1093/icb/icm039 (2007).

78. Coates, C. J. \& Nairn, J. Diverse immune functions of hemocyanins. Dev. Comp. Immunol. 45, 43-55 (2014).

79. Destoumieux-Garzon, D. et al. Crustacean immunity-Antifungal peptides are generated from the C terminus of shrimp hemocyanin in response to microbial challenge. J. Biol. Chem. 276, 47070-47077 (2001).

80. Lee, S. Y., Lee, B. L. \& Soderhall, K. Processing of an antibacterial peptide from hemocyanin of the freshwater crayfish Pacifastacus leniusculus. J. Biol. Chem. 278, 7927-7933 (2003).

81. Zhang, X. B., Huang, C. H. \& Qin, Q. W. Antiviral properties of hemocyanin isolated from shrimp Penaeus monodon. Antivir. Res. 61, 93-99 (2004). 
82. Velayutham, M. \& Munusamy, A. Humoral immune responses of antibacterial hemocyanin (Ab-Hcy) in mud crab Scylla serrata. Aquaculture 464, 428-433 (2016).

83. Yan, F. et al. Identification and agglutination properties of hemocyanin from the mud crab (Scylla serrata). Fish Shellfish Immunol. 30, 354-360 (2011).

84. Zerbino, D. R. \& Birney, E. Velvet: algorithms for de novo short read assembly using de Bruijn graphs. Genome Res. 18, 821-829. https://doi.org/10.1101/gr.074492.107 (2008).

85. Grabherr, M. G. et al. Full-length transcriptome assembly from RNA-Seq data without a reference genome. Nat. Biotechnol. 29, 644-652. https://doi.org/10.1038/nbt.1883 (2011).

86. Xie, C. et al. KOBAS 2.0: a web server for annotation and identification of enriched pathways and diseases. Nucleic Acids Res 39, 316-322. https://doi.org/10.1093/nar/gkr483 (2011).

87. Langmead, B., Trapnell, C., Pop, M. \& Salzberg, S. L. Ultrafast and memory-efficient alignment of short DNA sequences to the human genome. Genome Biol. 10, R25. https://doi.org/10.1186/gb-2009-10-3-r25 (2009).

88. Li, B. \& Dewey, C. N. RSEM: accurate transcript quantification from RNA-Seq data with or without a reference genome. $B M C$ Bioinform. 12, 323. https://doi.org/10.1186/1471-2105-12-323 (2011).

89. Schulze, S. K., Kanwar, R., Golzenleuchter, M., Therneau, T. M. \& Beutler, A. S. SERE: single-parameter quality control and sample comparison for RNA-Seq. BMC Genom. 13, 524. https://doi.org/10.1186/1471-2164-13-524 (2012).

90. Anders, S. \& Huber, W. Differential expression analysis for sequence count data. Genome Biol. 11, R106. https://doi.org/10.1186/ gb-2010-11-10-r106 (2010).

91. 91 Alexa A, Rahnenführer J. topGO: enrichment analysis for gene ontology. (2010)

92. Kanehisa, M., Sato, Y., Furumichi, M., Morishima, K. \& Tanabe, M. New approach for understanding genome variations in KEGG. Nucleic Acids Res. 47, D590-D595. https://doi.org/10.1093/nar/gky962 (2019).

93. Kanehisa, M. \& Goto, S. KEGG: Kyoto encyclopedia of genes and genomes. Nucleic Acids Res. 28, 27-30. https://doi.org/10.1093/ nar/28.1.27 (2000).

94. Kanehisa, M. Toward understanding the origin and evolution of cellular organisms. Protein Sci 28, 1947-1951. https://doi. org/10.1002/pro.3715 (2019).

\section{Acknowledgements}

This study was supported by the Natural Science Foundation of China (No. 31472294) and the Guangdong Provincial Project of Science and Technology (No. 2017B020204003). We would like to thank the anonymous reviewers for their helpful remarks and suggestions.

\section{Author contributions}

Z.N.X. wrote the main manuscript text. Z.N.X., A.L. carried out the experiments and analyzed the data. K.S.L and G.Z.W were involved in the data analysis and preparation of the manuscript. H.H.Y designed the experiments, analyzed the results, and prepared the manuscript. All authors approved and read the final manuscript.

\section{Competing interests}

The authors declare no competing interests.

\section{Additional information}

Supplementary information is available for this paper at https://doi.org/10.1038/s41598-020-70139-2.

Correspondence and requests for materials should be addressed to H.Y.

Reprints and permissions information is available at www.nature.com/reprints.

Publisher's note Springer Nature remains neutral with regard to jurisdictional claims in published maps and institutional affiliations.

(c) (i) Open Access This article is licensed under a Creative Commons Attribution 4.0 International cc) License, which permits use, sharing, adaptation, distribution and reproduction in any medium or format, as long as you give appropriate credit to the original author(s) and the source, provide a link to the Creative Commons license, and indicate if changes were made. The images or other third party material in this article are included in the article's Creative Commons license, unless indicated otherwise in a credit line to the material. If material is not included in the article's Creative Commons license and your intended use is not permitted by statutory regulation or exceeds the permitted use, you will need to obtain permission directly from the copyright holder. To view a copy of this license, visit http://creativecommons.org/licenses/by/4.0/.

(C) The Author(s) 2020 